\title{
UTILIZAÇÃO DE SISTEMA DE DIREÇÃO ELETRO-HIDRÁULICO EM ÔNIBUS COM MOTORES DIESEL
}

\author{
Bill, E. A. e Carreirão, C. M. \\ UTFPR - Universidade Tecnológica Federal do Paraná \\ edubill@hotmail.com, ccarreirao@hotmail.com
}

\section{RESUMO}

Sistemas de direção elétricos e eletro-hidráulicos têm sido utilizados em veículos leves durante muitos anos, a sua principal contribuição é o aumento do conforto e conveniência para o condutor. Nos últimos anos, o uso de veículos comerciais que usam motores elétricos ou híbridos tem aumentado muito, sendo liderado pelos mercados Europeu e Chinês. Com o uso de motores elétricos / híbridos, se fez necessário desenvolver algumas alternativas de geração de energia hidráulica para o sistema de direção, já que não há motor a combustão, ou ele permanece desligado por um determinado tempo. Vislumbrando este cenário, muitas empresas começaram a usar sistemas de direção eletro-hidráulica, o ponto principal é conectar a bomba de direção a um motor elétrico, em vez de usar o motor a combustão. Este artigo irá explorar este sistema, apresentar as principais vantagens e desvantagens do sistema, explicar como o mesmo funciona e avaliar a economia de combustível em sua instalação em um ônibus com motor diesel.

\section{INTRODUÇÃO}

Os últimos anos trouxeram para as montadoras uma série de desafios, entre eles pode-se citar a redução no nível de emissão de poluentes, a redução no consumo de combustíveis fósseis e a redução dos custos de produção e fabricação. O maior desafio é o atingimento de todos esses objetivos com custo acessível e sem decréscimo de qualidade para o cliente final.

Um item que se alinha a esses desafios é a utilização de sistemas de direção eletro-hidráulicos para ônibus. Esse sistema vem sendo difundido juntamente com a entrada de veículos híbridos e elétricos no mercado nacional e internacional. O sistema não depende do tradicional motor diesel, portanto, se instalado em veículos puramente diesel, poderia trazer redução em consumo de combustível, com consequente redução na emissão de poluentes, maior conforto para o motorista em função da opção de plena assistência em manobras com o veículo parado, além de um menor custo de montagem e menor quantidade de componentes. Esse artigo terá como objetivo estudar os sistema hidráulico e eletro-hidráulico, compará-los no funcionamento e composição e, 
finalmente, apresentar um estudo de redução no consumo de combustível com a introdução do sistema eletro-hidráulicos em veículos utilizando trem de força totalmente movido a diesel.

\section{EXPLICANDO OS SISTEMAS}

Veículos comercias, nesse caso ônibus, trafegam com cargas variáveis ao longo do dia, porém, em horários de pico chegam facilmente ao limite de carga legal, que é de 16 toneladas para veículos dotados de suspensão pneumática e 4 apoios no solo, sendo dois destes trativos[4]. Para permitir a manobrabilidade de tais veículos, faz-se necessário um sistema de direção hidráulica. Esse sistema reduz drásticamente o esforço empregado pelo motorista para realização de manobras. O sistema hidráulico é responsável por gerar $80 \%$ da força necessária durante o esterçamento, ou seja, somente $20 \%$ do esforço total é realizado pelo motorista [10].

\subsection{Sistema direção convencional (HS - hydraulic steering)}

O sistema de direção hidráulica convencional é composto, em resumo, por uma bomba hidráulica, geralmente do tipo palheta, tubulação, reservatório e caixa de direção, conforme mostrado na Figura 1.

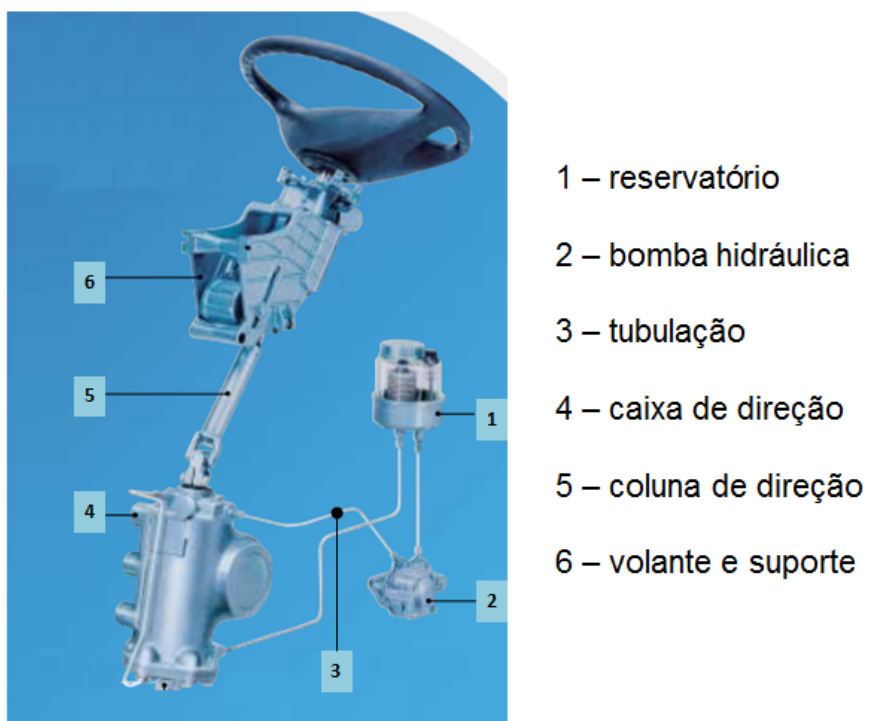

Figura 1 - Sistema de direção hidráulica Fonte: $\mathrm{O}$ autor, adaptado de [2]

Nesse sistema a bomba é conectada ao motor diesel através de engrenagens ou polias, portanto não há controle direto de vazão e pressão. Essas propriedades dependem da rotação da bomba, rotação esta que é diretamente proporcional à rotação do motor. No sistema convencional a seleção da bomba é baseada no pior cenário possível, que seria o motor trabalhando em sua menor rotação, a rotação de marcha lenta. Nessa condição específica de trabalho necessíta-se de pleno auxílio hidráulico para execução de manobras com o veículo parado. Nas equações (1) e (2) pode-se observar a dependência de propriedades como vazão e pressão em função da rotação de trabalho. 


$$
\begin{gathered}
Q=\frac{V \times n \times \eta_{v o l}}{1000} \\
p=\frac{600 \times \eta_{\text {ges }} \times P_{\text {acion }}}{Q}
\end{gathered}
$$

Onde: Q=vazão [l/min]; V=volume nominal [ $\left.\mathrm{cm}^{3}\right] ; \mathrm{n}=$ rotação de acionamento da bomba [min-1]; $\eta$ vol=rendimento volumétrico; ๆges=rendimento total; p=pressão [bar]; Pacion=potência de acionamento da bomba [kW].

Como o sistema é planejado para oferecer plena assistência já na rotação de marcha lenta, conclui-se que, para todas as outras faixas de rotação acima desta, gera-se energia hidráulica que não será efetivamente utilizada [7]. Além disso, muitas bombas possuem uma válvula reguladora de vazão, que mantém a vazão constante mesmo com o aumento da rotação, vide Gráfico 1 abaixo. Em resumo, gera-se uma vazão proporcional à rotação da bomba e, em seguida, baixa-se essa vazão para a faixa de trabalho que é definida como ideal.

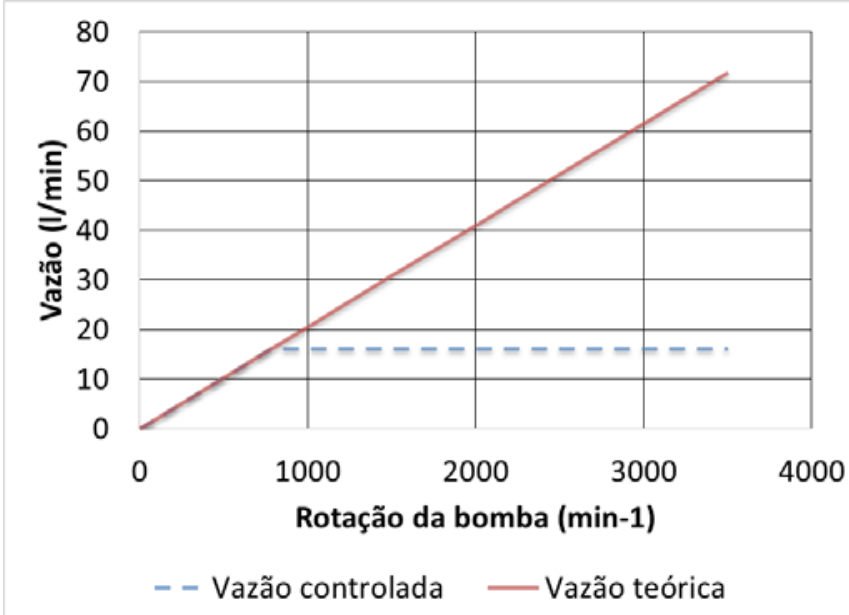

Gráfico 1 - Vazão controlada e vazão teórica

Fonte: $\mathrm{O}$ autor

\subsection{Sistema eletro-hidráulico (EHPS - Electro-hydraulic Power Steering)}

Objetivando a redução no consumo de combustível, alguns veículos híbridos desligam seus motores diesel em determinados momentos e trafegam apenas com seu motor trativo elétrico acionado. Esse modo de operação impossibilita a utilização do sistema de assistência de direção convencional, já que o mesmo é dependente do motor diesel. Essa restrição de operação proporcionou o desenvolvimento e aplicação do sistema de direção eletro-hidráulico, que é o objeto de estudo deste artigo.

O sistema de direção eletro-hidráulico para veículos pesados é composto por um motor elétrico, uma bomba hidráulica, que neste estudo é uma bomba de engrenagens de baixa pulsação, tubos e mangueiras hidráulicas, um inversor de potência e chicotes e cabos elétricos. Esse sistema pode ser visto em resumo na Figura 2. 


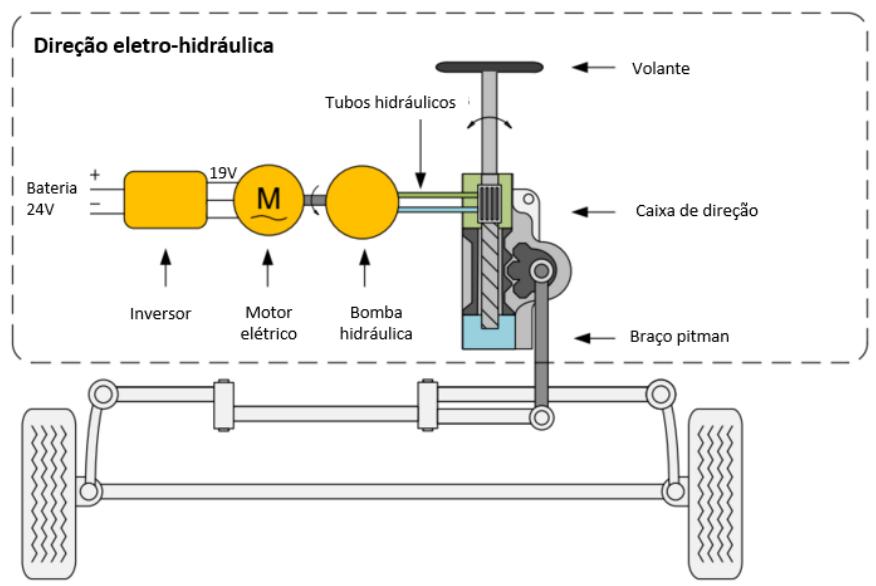

Figura 2 - Sistema de direção eletro-hidráulica Fonte: O autor, adaptado de [8].

Nesse sistema a bomba hidráulica é conectada diretamente ao motor elétrico, que é conectado ao inversor. A tensão de $24 \mathrm{~V}$ contínua, gerada pela bateria, alimenta o inversor de potência, que converte a tensão original para 19V trifáfiso, tensão esta que alimenta o motor elétrico.

Já que a bomba deste sistema não está conectada ao motor diesel, mas sim ao motor elétrico, a seleção da mesma não precisa ser mais efetuada com base na rotação de marcha lenta do motor. Nesse sistema pode-se utilizar uma bomba com vazão nominal menor, que, geralmente, é mais barata, e trabalhar com uma rotação mais alta no motor elétrico para compensar essa diferença de vazão nominal.

Já que agora pode-se controlar a rotação de forma eficiente, aumentando ou baixando conforme necessário, pode-se afirmar que não será gerada energia hidráulica além da necessária, pois se terá somente a quantidade de energia que será efetivamente utilizada pelo sistema.

Além dos pontos anteriormente citados, com a introdução deste sistema se exclui um agregado do motor, ou seja, haverá um componente a menos para o motor movimentar.

Os componentes utilizados no sistema eletro-hidráulico em estudo nesse trabalho são mostrados nas Figura 3, Figura 4 e Figura 5, a seguir:

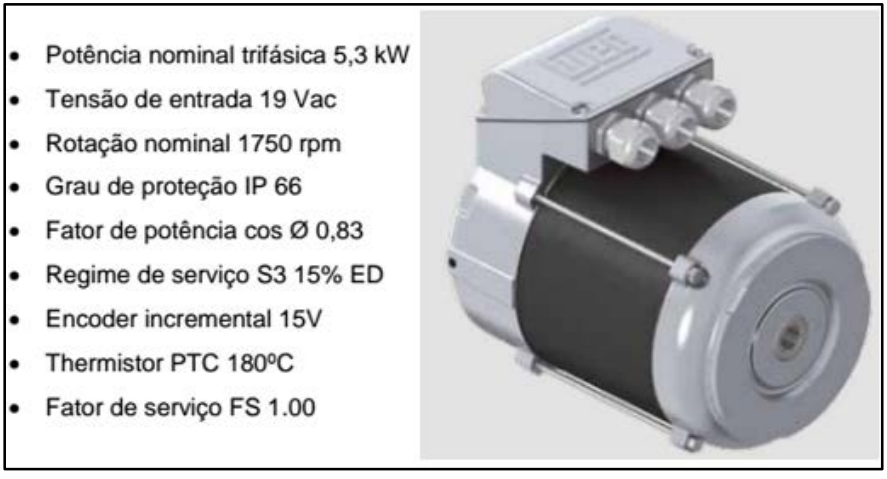

Figura 3 - Motor elétrico trifásico

Fonte: $\mathrm{O}$ autor, adaptado de [9] 


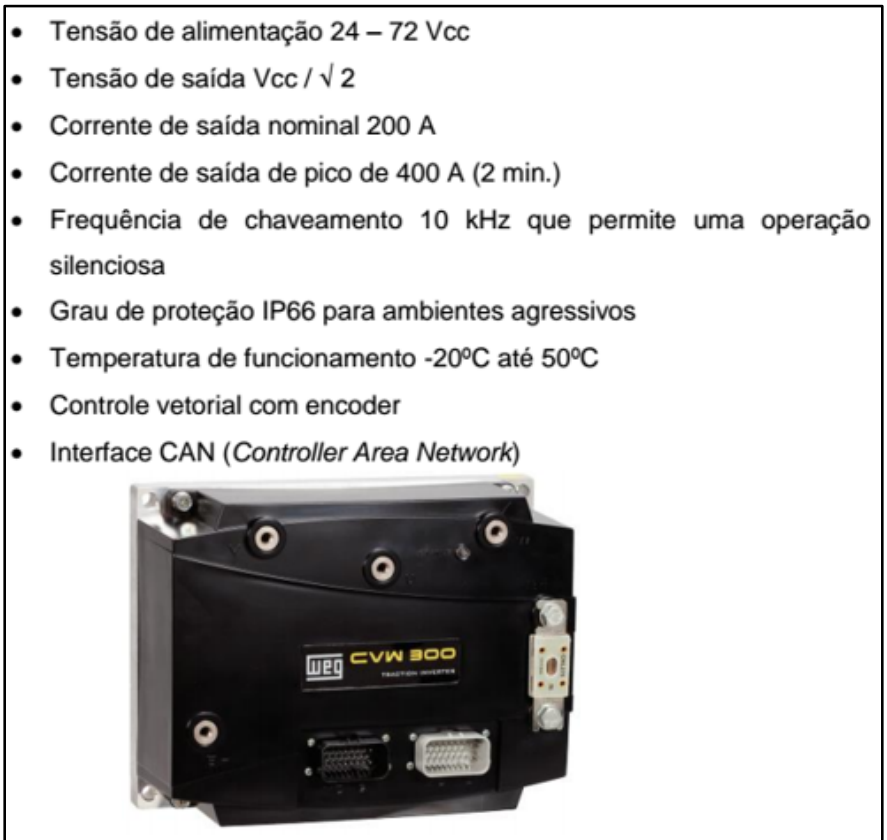

Figura 4 - Inversor de potência

Fonte: $\mathrm{O}$ autor, adaptado de [9]

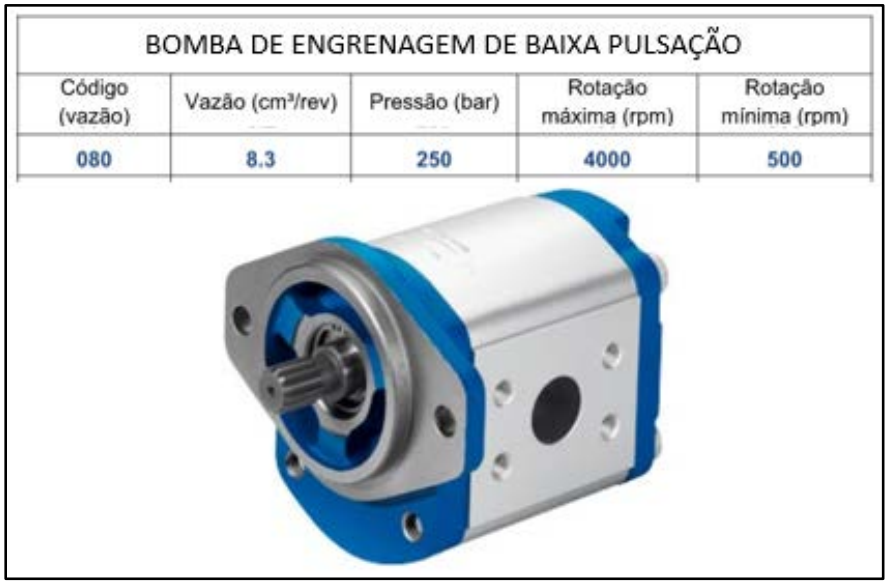

Figura 5 - Bomba hidráulica de baixa pulsação

Fonte: $\mathrm{O}$ autor, adaptado de [9]

\section{VANTAGENS E DESVANTAGENS}

\subsection{Funcionamento}

No sistema de direção convencional a bomba é ligada ao motor diesel e permanece em funcionamento durante todo período em que o veículo está ligado. Independente do veículo estar parado ou em movimento, haverá consumo de energia por este componente. Válvulas posicionadas ao longo do sistema controlam sua pressão e direcionam o fluxo de óleo corretamente. Caso o veículo permaneça ligado, mas sem movimentação do volante, ainda haverá circulação de óleo pelo sistema e, consequente, perda de energia. 
Já o sistema eletro-hidráulico trabalha somente quando há necessidade. O motor elétrico acoplado à bomba hidráulica permanece desativado até que haja rotação no volante. Para leitura dessa rotação é utilizado um sensor de giro e velocidade do volante conforme Figura 6.

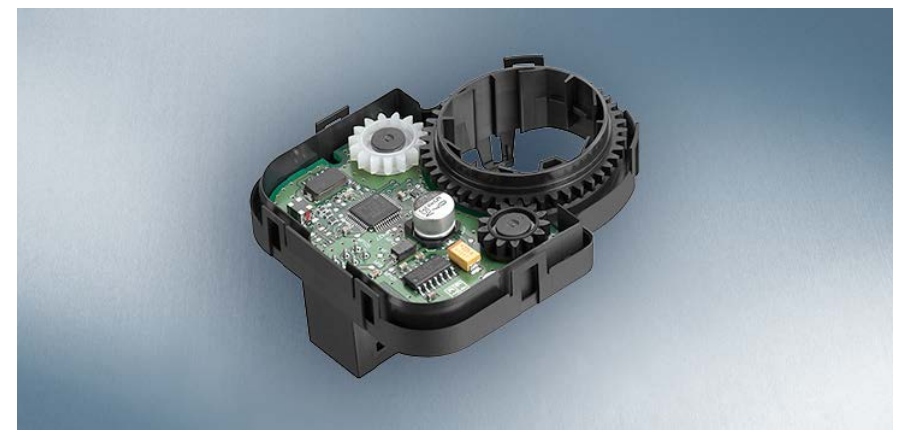

Figura 6 - Sensor de giro do volante Fonte: [3]

Os parâmetros de velocidade de giro do volante e velocidade do veículo são enviados a uma ECU dedicada ao sistema de direção, que define a vazão e pressão necessárias para aquela situação e aciona o motor a uma determinada rotação, considerada ideal. Caso não haja movimentação do volante por um determinado período de tempo, que é ajustável pelo fabricante, o sistema automaticamente se desliga e evita o desperdício energético.

\subsection{Instalação}

Nesse estudo serão comparados um sistema de direção para um ônibus com motor traseiro, conforme Figura 7.

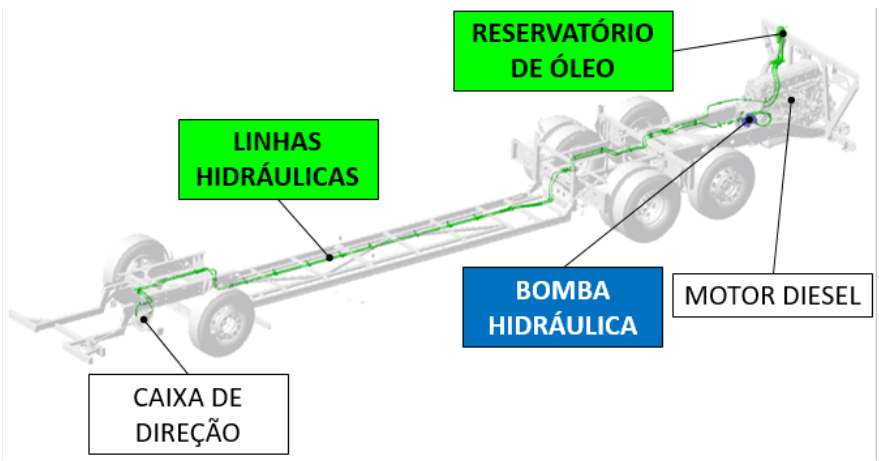

Figura 7 - Componentes em ônibus com sistema de direção convencional Fonte: $\mathrm{O}$ autor.

Em ônibus com motor traseiro a bomba do sistema de direção convencional fica acoplada ao motor, deste modo diversos tubos e mangueiras são necessários para conectar o reservatório até a bomba, a bomba até a caixa de direção e a caixa de direção até o reservatório novamente.

Quando se opta pela utilização do sistema eletro-hidráulico, há liberdade para instalação do mesmo onde melhor convir, já que o mesmo trabalha isoladamente do motor diesel. Uma opção de instalação é próximo à caixa de direção, deste modo, a quantidade de tubos e mangueiras hidráulicas pode ser otimizada ao máximo. A escolha desse sistema significa a utilização de um 
módulo simples e compacto, de fácil instalação, com menor quantidade de peças e menor tempo de montagem.

Na Figura 8 abaixo pode-se visualizar o módulo do sistema de direção eletro-hidráulico instalado na região frontal do veículo.

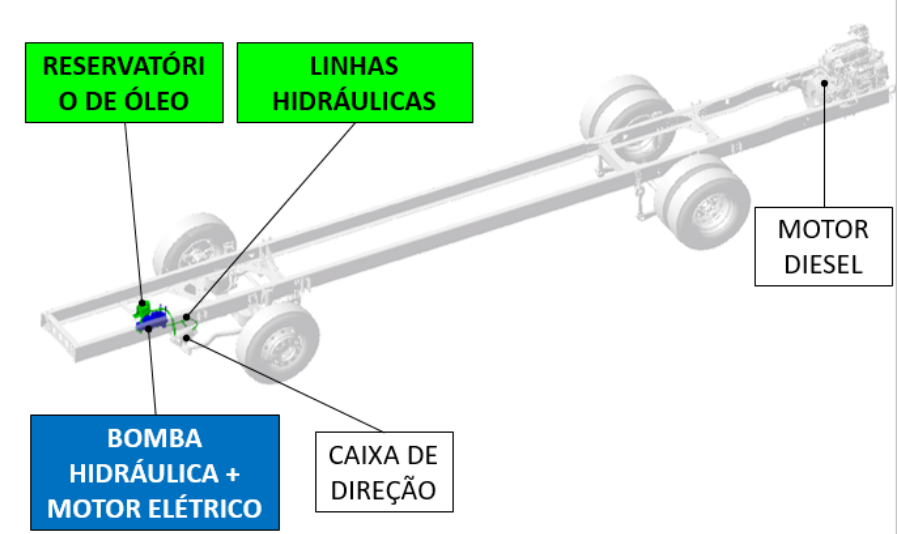

Figura 8 - Componentes em ônibus com sistema de direção eletro-hidráulico Fonte: $\mathrm{O}$ autor

\subsection{Custo}

Sendo os dados de custo do produto sigilosos, optou-se por fazer a comparação dos custos dos dois sistemas e apresentar aqui somente a diferença bruta de custo entre os mesmos. O veículo utilizado nesta comparação é um ônibus urbano, 4x2, como motor de 7 litros, traseiro e entre eixos de $6300 \mathrm{~mm}$.

Com a remoção de todo o sistema hidráulico convencional e a adição do sistema eletro-hidráulico existe a adição de aproximadamente $\mathrm{R} \$ 2.400$ ao custo do produto. Esse dado será utilizado posteriormente para avaliar o tempo em que o custo adicional do sistema seria amortizado.

Embora a adição inicial de custo ao produto seja considerável, o custo dos componentes poderia ser reduzido através de um aumento no volume de vendas e maior oferta no mercado de reposição. A nacionalização dos principais componentes, que hoje são importados e ficam suscetíveis à variação cambial, poderia também auxilar a baixar o custo.

A base econômica desta análise é de janeiro de 2016 e não foram considerados fatores não relacionados aos componentes em si, como tempo de montagem, espaço para estoque e quantidade de itens diferentes no veículos.

\section{CONSUMO DE COMBUSTÍVEL}

\subsection{Aquisição de Dados}

Para realização de uma estimativa de redução no consumo de combustível, um ônibus urbano, 4x2, mostrado na Figura 9 com motorização híbrida paralela seguindo a especificação da Tabela 1 a seguir, foi instrumentado e os dados a seguir foram extraídos: rotação e torque do motor 
elétrico do sistema de direção através de instrumentação específica e rotação do motor diesel e velocidade do veículo através da rede CAN.

\begin{tabular}{c|c|c|c}
\hline \multicolumn{4}{c}{ VOLVO HÍBRIDO B5RH, B215RH } \\
\hline Componente & Especificação & Potência & Torque \\
\hline MOTOR DIESEL & D5E & $210 \mathrm{cV}$ & $800 \mathrm{Nm}$ \\
\hline MOTOR DE TRAÇÃO ELÉTRICO & I-SAM & $160 \mathrm{cV}$ & $800 \mathrm{Nm}$ \\
\hline TRANSMISSÃO & \multicolumn{3}{|c}{ I-SHIFT DE 12 MARCHAS }
\end{tabular}

Tabela 1 - Dados do trem de força do veículo de referência Fonte: [12]

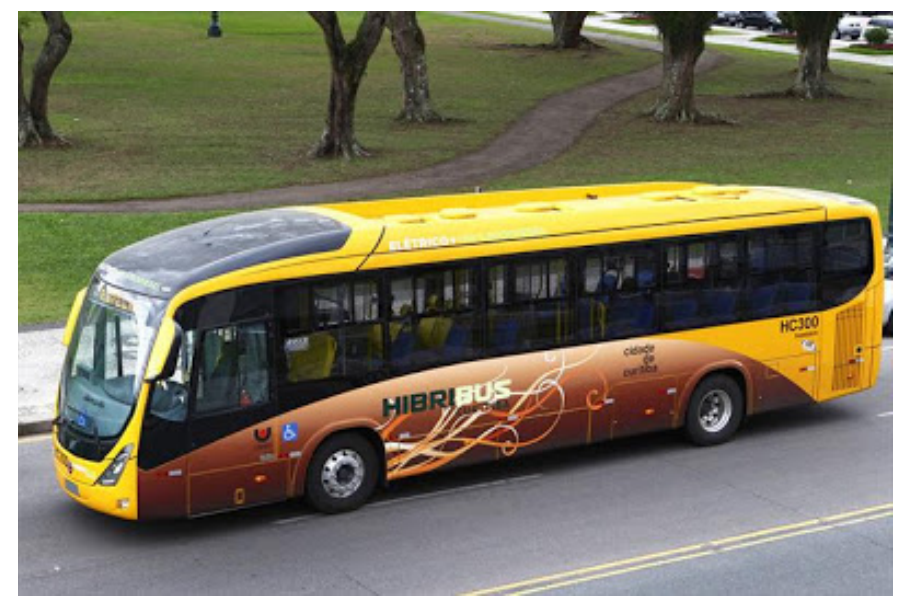

Figura 9 - Veículo utilizado nos testes

Fonte: [12]

A aquisição de dados foi feita em uma rota real de utilização do veículo, em condição normal de operação, localizada na cidade de Curitiba, conforme mostrado na Figura 10. Optou-se pela aquisição de dados em uma rota real para se chegar ao resultado mais próximo daquele encontrado pelo cliente. Essa rota é de regime urbano, com típicas paradas próximas entre si e velocidade média de aproximadamente $25 \mathrm{~km} / \mathrm{h}$. 


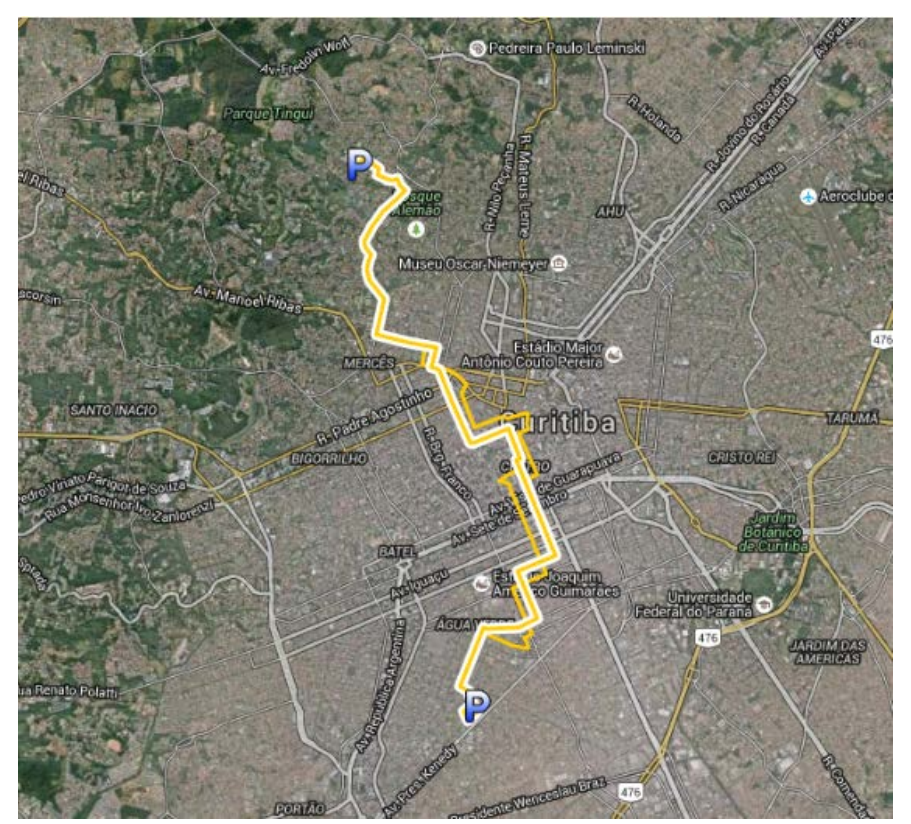

Figura 10 - Rota Mercês Guanabara, Curitiba

Fonte: [9]

\subsection{Tratamento dos Dados}

Com os dados de rotação e torque gerado pelo motor elétrico e utilizando a equação (3), calculouse a potência dissipada pelo motor elétrico:

$$
P_{\text {dissipada }(E H P S)}=\frac{2 \times \pi \times n \times T}{60 \times 1000}
$$

Onde: P=potência [kW]; n=rotação do motor [RPM]; T=torque do motor elétrico [Nm]

Para calcular a vazão específica para cada instante de tempo a equação (1) foi utilizada.

Como resultado destas análises obteve-se o consumo de energia instantâneo necessário para gerar a vazão desejada. Notou-se que quando o veículo está parado e não há movimento no volante, o sistema automaticamente se desliga, conforme já explicado na sessão anterior. Nesses momentos não há consumo nenhum de energia no sistema eletro-hidráulico.

Após essa primeira etapa e através da rotação do motor diesel obtida da rede de comunicação CAN, calculou-se qual seria o consumo de energia hipotético caso, ao invés de um sistema eletrohidráulico, o veículo estivesse utilizando uma bomba convencional conectada ao motor diesel. Vale salientar que, quando a bomba é montada no motor diesel, a mesma trabalha sempre que o mesmo está ligado, pois não há qualquer modo de desligá-la, ou seja, mesmo quando o veículo está parado e não há rotação do volante, existe o consumo de energia.

Para esta análise calculou-se a vazão teórica com base na rotação do motor, a partir da equação (1). 
Depois, tendo-se a vazão, calculou-se a energia dissipada na bomba utilizando-se as equações (4) e (5).

$$
\begin{gathered}
P_{\text {dissipada }(H P S)}=\frac{p \times Q}{600 \times \eta_{g e s}} \\
\eta_{g e s}=\eta_{V} \times \eta_{M}
\end{gathered}
$$

Onde: $\mathrm{Q}=$ vazão $[1 / \mathrm{min}] ;$ ๆges=rendimento total; $\eta \mathrm{V}=$ rendimento volumétrico; $\eta \mathrm{M}=$ =rendimento hidráulico mecânico; $\mathrm{p}=$ pressão [bar].

Tendo as potências dissipadas pelo sistema eletro-hidráulico e teoricamente pelo sistema convencional gerou-se o Gráfico 2, onde é comparado o consumo de energia para cada sistema. Comparando os sistemas, observa-se uma redução média no consumo energético de $71 \%$. Enquanto na média o consumo do sistema hidráulico gira em torno de $0,52 \mathrm{~kW}$, no sistema eletrohidráulico esse valor é de $0,15 \mathrm{~kW}$. Os fatores relevantes para essa diferença estão basicamente relacionados ao dimensionamento dos sistemas e ao seu princípio de funcionamento otimizado. Enquanto no sistema eletro-hidráulico se gera a vazão correta para cada momento, no sistema convencional a vazão correta já é gerada na rotação de marcha lenta do motor. Para todas as outras rotações acima da marcha lenta há perda, pois a vazão teórica aumenta e, para controlá-la, é inserida uma válvula de controle de vazão no sistema. Em ônibus essa válvula reguladora de vazão geralmente está incorporada à bomba hidráulica.

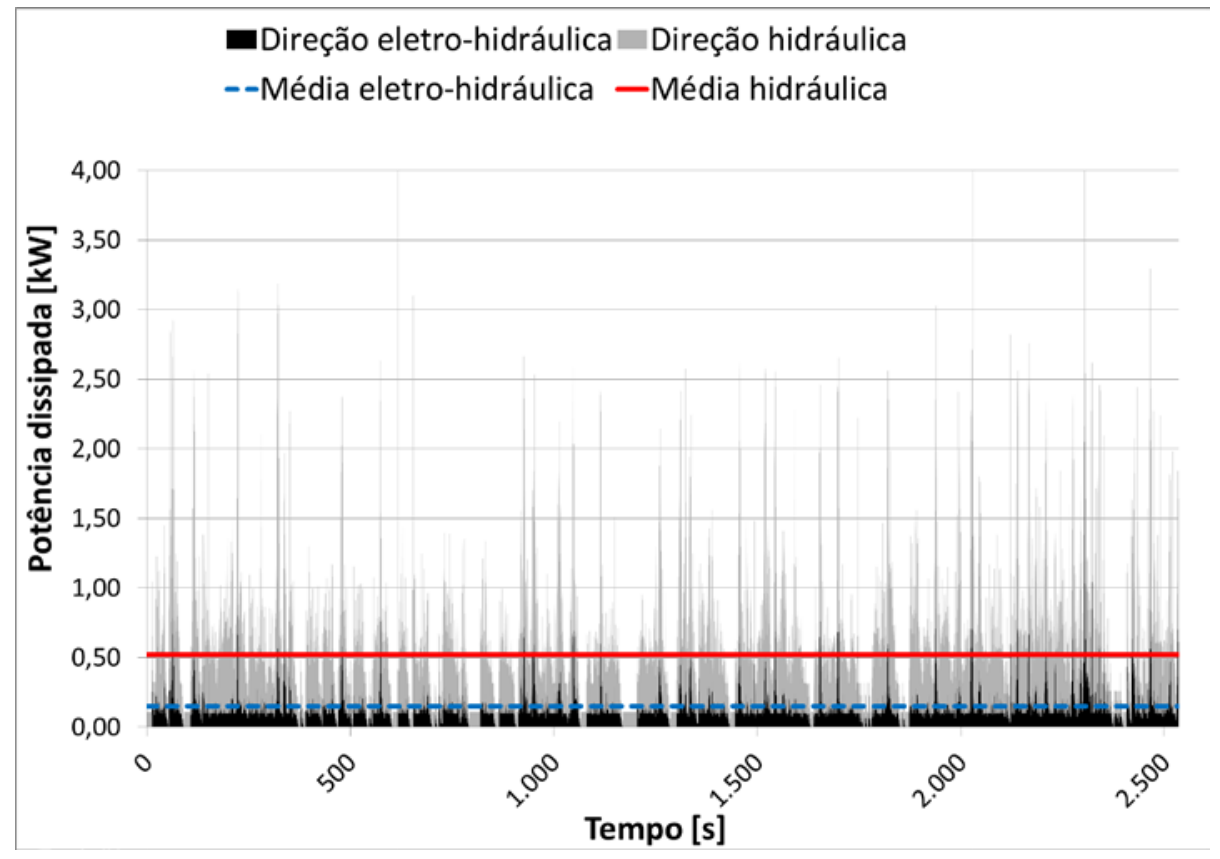

Gráfico 2 - Comparativo entre a energia dissipada pelos dois sistemas Fonte: $\mathrm{O}$ autor.

Também vale citar que toda a energia dissipada pela bomba no sistema convencional vem do motor diesel, logo, quando a mesma é retirada e é conectada a um motor elétrico, deixa-se de gastar energia para movimentar movimentando este componente. 


\subsection{Redução no Consumo de Combustível}

Para medição de uma suposta redução no consumo de combustível com a instalação do sistema eletro-hidráulico em veículos diesel convencionais, optou-se pelo cálculo energético do sistema hidráulico. O objetivo é que com a utilização do sistema eletro-hidráulico, a bomba hidráulica da direção seja removida do motor e desta forma haja redução no consumo de óleo diesel.

Para o cálculo de redução no consumo de combustível, optou-se pela utilização de uma amostragem do ciclo de medição da potência anteriormente citado. Ao invés de considerarmos todo o ciclo de medição, optou-se pela seleção da parte mais representativa de um ciclo urbano. Este período está compreendido entre o tempo de 300s até 1500s. O trecho do ciclo selecionado para os estudos deste artigo está representado no Gráfico 3.

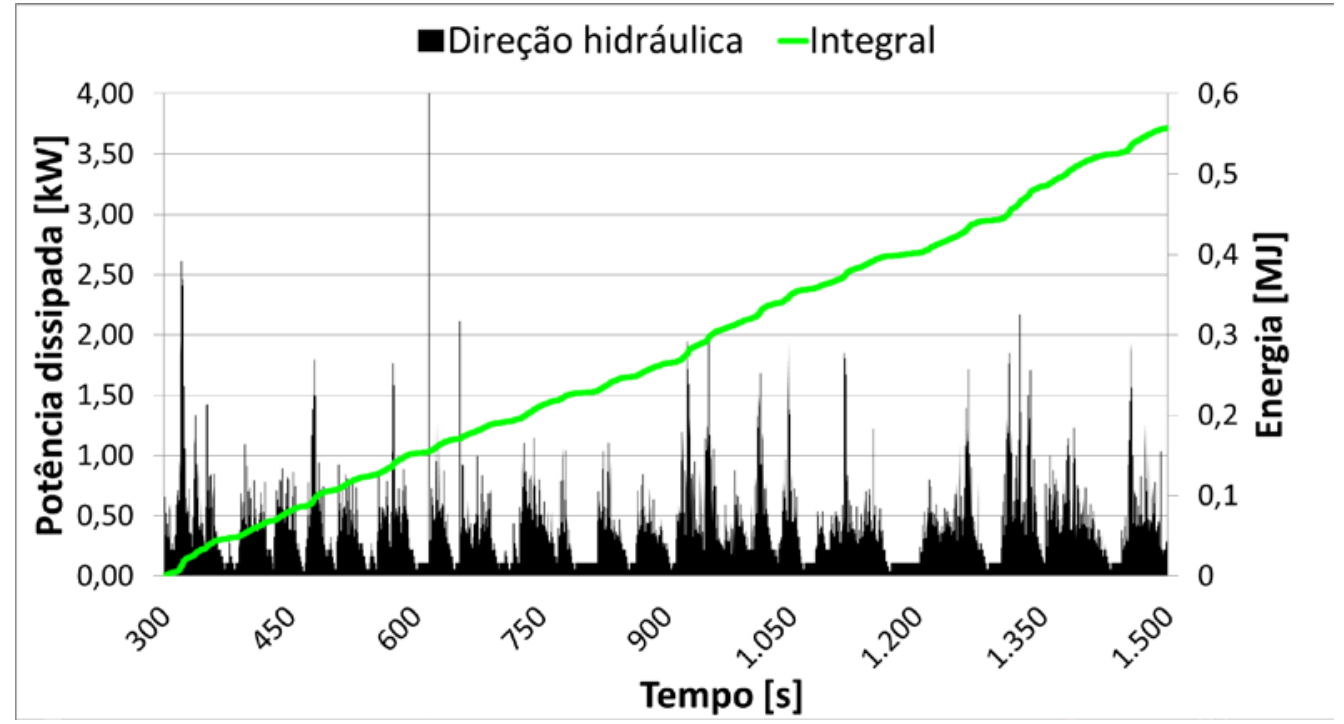

Gráfico 3 - Amostra de consumo energético representando ciclo urbano Fonte: $\mathrm{O}$ autor

Conhecendo a curva de potência, efetuou-se a integração da mesma e, desta forma, obteve-se a curva de consumo energético para este período de 1200s. A integração foi efetuada utilizando o método das áreas dos retângulos, através do software Matlab. Esse resultado é mostrado no Gráfico 3.

O resultado desta integral representa o consumo energético total do período de 1200s. Nesse caso específico, o valor resultante da análise foi de 560kJ.

Sabendo que o poder calorífico do diesel é de $44351 \mathrm{~kJ} / \mathrm{kg}$ [5] e a eficiência média de um motor diesel é de 45\% [6], se obteve a quantidade de diesel utilizada, em quilogramas, no período. Para a conversão do valor obtido de quilogramas para litros, utilizou-se a densidade de 8888 kg/l [5].

Para esse período de amostra de 1200s, em ciclo urbano, se obteve uma redução de consumo de combustível média de 0,0663 l/h. 
Com esse dado disponível, extrapolou-se a redução do consumo para um período de um ano. Os dados utilizados na extrapolação foram obtidos de [11] e são mostrados abaixo:

- Tempo de operação diária: 12 horas;

- Dias de operação por semana: 7 dias;

- Dias de operação anual: 345 dias (descontando 20 dias para manutenção em geral).

Inserindo os dados acima no estudo de caso obtêm-se uma redução de consumo anual de combustível de 274,48 litros. Considerando o preço médio do diesel para a região de Curitiba sendo de 2,927 reais/l [1], se obtém uma redução de aproximadamente $\mathrm{R} \$ 803,40$. Deste modo pode-se prever que, caso o proprietário opte pela aquisição de um veículo com o sistema eletrohidráulico, o mesmo estará totalmente amortizado em cerca de 3 anos já que, como citado anteriormente, a adição de peças ao sistema representa $\mathrm{R} \$ 2.400$. O custo de manutenção não foi considerado nesta análise por ser semelhante entre os dois sistemas, já que incluí basicamente eventuais trocas de óleo e filtro de óleo.

\section{CONCLUSÃO}

A introdução do sistema de direção eletro-hidráulica em veículos pesados está cada vez mais perto de se tornar uma realidade. O maior empecilho hoje é o maior custo agregado ao veículo que, como visto neste artigo, é R $\$ 2.400$ mais caro que uma direção hidráulica.

É importante uma mudança de visão relativa ao custo de um produto. É necessário que pensemos no custo operacional do produto e não somente no seu custo de produção. Nesse sentido a introdução do sistema elétro-hidráulico aumenta o custo do produto porém diminuí o seu custo operacional. Olhando nesse prisma, o sitema elétro hidráulico é viável.

Vale salientar que a análise de custo deste artigo foi baseado no cenário econômico de 2016, onde cada real representa 0,25 euros. Caso haja valorização da moeda brasileira, a introdução do sistema eletro-hidráulico se torna ainda mais interessante e seu tempo de amortização diminui.

Esta última análise nos remete também a necessidade de investimento na nacionalização de componentes, de tal forma que as flutuações cambiais não afetem o retorno de investimento e o custo do produto.

Esse artigo teve como objetivo principal desmistificar os maiores custos envolvidos nesse novo sistema. Foi provado que o sistema se amortiza em 3 anos e, quando se extrapola essa redução para uma frota de veículos, o números totais começa a se tornar mais atrativos. 
Como sugestão para trabalhos futuros pode-se indicar o cálculo de redução na emissão de poluentes e uma análise de redução de consumo de combustível em dois veículos reais e iguais, porém um utilizando o sistema eletro-hidráulico e o outro o sistema convencional.

\section{REFERENCIAS}

[1] ANP. Preço médio por município, disponível em <http://www.anp.gov.br/preco/prc/Resumo_Por_Municipio_Posto.asp>. Acesso em 11/02/2016. [2] BOSCH. Steering Systems and Accessories for Commercial Vehicles, disponível em: $<$ http://www.bosch-automotivesteering.com/fileadmin/_migrated/content_uploads/LENKSYSTEME_NKW_E.pdf>. Acesso em 18/01/2016.

[3] BOSCH 2. Sensores, disponível em: <http://pt.boschautomotive.com/pt/internet/parts/parts_and_accessories/motor_and_sytems/electronic_driving_sa fety_systems/sensors_2/sensors_8.html\#>. Acesso em 24/01/2016.

[4] CONTRAN. Resolução $\mathrm{n}^{\mathrm{o}} 210$, disponível em: <http://www.denatran.gov.br/download/Resolucoes/RESOLUCAO_210.rtf $>$. Acesso em 07/12/2015.

[5] FERNANDES, A. Análise do Desempenho de Motor Diesel com a Utilização de Biocombustível Obtido a Partir do Reuso de Óleo Vegetal, Faculdade de Engenharia, Arquitetura e Urbanismo, Universidade Metodista de Piracicaba, Santa Bárbara d’Oeste, Brasil, 2012.

[6] FERREIRA, S. L.; SANTOS, A. M.; SOUZA, G. R. Análise por cromatografia gasosa de BTEX nas emissões de motor de combustão, Quim. Nova, São Paulo, Brasil, p. 539-545, 2008.

[7] KOZUMA, F.; ARITA, T.; TSUDA, H. Development of Energy Saving Power Steering, Symposium on Fluid Power, Tsukuba, Japão, JFPS International, p. 297-300, 2005.

[8] MORTON, C.; SPARGO, C. M. Electrified Hydraulic Power Steering System in Hybrid Electric Heavy Trucks, IET Electrical Systems in Transportation, Newcastle, Reino Unido, IET, p. 70-77, 2014.

[9] ROSA, M. C. Sistema de Direção Elétrica Assistida para Veículos Elétricos e Híbridos Utilizando Motor de Indução Trifásico, Universidade Tecnológica Federal do Paraná, Curitiba, Brasil, 2015.

[10]SUN, Y,; HE P.; ZHANG, Y.; CHEN, L. Modeling and Co-simulation of Hydraulic Power Steering System, Third International Conference on Measuring Technology and Mechatronics Automation, Wuhan, China, IEEE, p. 595-600, 2011.

[11]URBS. Horário de ônibus, disponível em: <http://www.urbs.curitiba.pr.gov.br/horario-deonibus/160>. Acesso em 12/02/2016.

[12]VOLVO. Folheto ônibus híbrido, disponível em <http://www.volvobuses.com/bus/brazil/ptbr/linha-produtos/urbanos/volvo-hibrido/Documents/folheto-onibus-hibrido-2014.pdf>. Acesso em 24/01/2016. 